Comparison of New and Legacy TATBs

D. M. Hoffman, T. M. Willey, A. R. Mitchell, S. C. DePiero

November 9, 2007

Journal of Energetic Materials 
This document was prepared as an account of work sponsored by an agency of the United States government. Neither the United States government nor Lawrence Livermore National Security, LLC, nor any of their employees makes any warranty, expressed or implied, or assumes any legal liability or responsibility for the accuracy, completeness, or usefulness of any information, apparatus, product, or process disclosed, or represents that its use would not infringe privately owned rights. Reference herein to any specific commercial product, process, or service by trade name, trademark, manufacturer, or otherwise does not necessarily constitute or imply its endorsement, recommendation, or favoring by the United States government or Lawrence Livermore National Security, LLC. The views and opinions of authors expressed herein do not necessarily state or reflect those of the United States government or Lawrence Livermore National Security, LLC, and shall not be used for advertising or product endorsement purposes. 


\title{
Comparison of New and Legacy TATBs ${ }^{\dagger}$
}

\author{
D. Mark Hoffman*, Trevor M. Willey, \\ Alexander R. Mitchell and Sabrina C. DePiero \\ $\mathrm{L}-282$ \\ Phone: 925 422-7759 \\ Fax: 924 424-3281 \\ Lawrence Livermore National Laboratory \\ Livermore, CA 94550
}

\begin{abstract}
Two newly synthesized versions of the insensitive high explosive (IHE) 1,3,5triamino-2,4,6-trinitrobenzenes (TATBs) were compared to two legacy explosives currently used by the Department of Energy. Except for thermal analysis, small scale safety tests could not distinguish between the different synthetic routes. Morphologies of new TATBs were less faceted and more spherical. The particle size distribution of one new material was similar to legacy TATBs, but the other was very fine. Densities and submicron structure of the new TATBs were also significantly different from the legacy explosives. Pressed pellets of the new explosives were less dense. Recrystallization from sulfolane improved the density and thermal stability of both new TATBs, though the morphology of the recrystallized TATB was nearly hexagonal platelets.
\end{abstract}

\section{Introduction}

Modern Department of Energy (DOE) weapons systems gain enhanced safety from plastic bonded explosives (PBXs) which contain the insensitive high explosive (IHE) 1,3,5-triamino-2,4,6-trinitrobenzene (TATB) bonded together with *to whom correspondence should be addressed. E-mail: hoffman2@llnl.gov

† This work performed under the auspices of the U.S. Department of Energy by Lawrence Livermore National Laboratory under Contract DE-AC52-07NA27344. 
Kel-F 800 , a copolymer of vinylidene fluoride and chlorotrifluoroethylene.

Currently LLNL has limited wet-aminated TATB reserves for formulation.

Although TATB is being synthesized and may soon be commercially available, the synthesis processes have changed and the explosive must be re-evaluated. Legacy wet and dry-aminated TATB have not been synthesized in the US in any significant quantity since about 1985 . Furthermore, significant quantities of the PBXs based on TATB/Kel-F (LX-17 and PBX 9502) have not been formulated since about $1990 .^{1}$ Over the last few years as part of a DOD MANTECH, Thiokol $^{2}$ and Holston Army Ammunition Plant $(\mathrm{HAAP})^{3}$ have produced moderate quantities of TATB ( $\sim 5 \mathrm{~kg}$ batches) with plans to scale up for DOD applications. Thiokol TATB is polycrystalline with an average particle size of about $40 \mu \mathrm{m}$ (similar to WA TATB) but HAAP TATB is only 5-6 $\mu \mathrm{m}$ (similar to ultrafine). Small quantities of these materials were obtained from the Naval Air Warfare Center at China Lake, $\mathrm{CA}^{4}$ for evaluation.

Characterization of the four TATBs: the new BAE Holston and ATK Thiokol and legacy wet (WA) and dry (DA) aminated TATB which are no longer manufactured in the US is the subject of this paper. Small scale safety data on these TATBs are unable to distinguish between them except that newer TATBs decompose thermally about $10^{\circ} \mathrm{C}$ below the decomposition temperature of dry aminated TATB which is about $5^{\circ} \mathrm{C}$ below that of wet aminated. The morphology of these TATBs was characterized by scanning electron microscopy. The density of compression molded disks approached the average density of the TATB 
crystals with increasing pressure. Ultra small angle $x$-ray scattering (USAX) measurements on pressed pellets showed different interfacial characteristics for ATK TATB compared to the others. Density distributions of new TATB crystals were substantially less than old crystals as measured using a gradient column. It may be possible to remove some of the impurities and improve the crystal structure of these TATBs by recrystallization. To that end small scale recyrstallization of BAE and ATK TATB from sulfolane produced crystals with density and thermal decomposition temperatures comparable to wet aminated TATB.

\section{Experimental:}

Legacy wet and dry aminated TATB used in these experiments was originally synthesized by Aerojet Corporation, sold to Holston Army Ammunition Plant and given lot numbers 12-03-82-0324-273 and 13-03-85-0307-538, respectively. Sample quantities of these TATB's were obtained by LLNL and given the lot numbers C-090 and C-084. Five hundred grams each of three different lots of Thiokol (ATK) and Holston (BAE) TATB were graciously provided by the Naval Surface Warfare Center at China Lake, CA. All of the tests described in this paper used ATK lot TATB001 and BAE lot BAE6E295-001, hereafter referred to as C-562 or C-559, respectively.

All explosives used at LLNL are subjected to small-scale safety tests including impact sensitivity, friction, spark and two thermal stability tests known as 
chemical reactivity (CRT) and differential scanning calorimetry (DSC) tests prior to other evaluation or use in prototype devices. A thorough critique of various small-scale tests is given elsewhere. ${ }^{5,6}$

Morphological comparisons of the various TATBs were made using a LEO 438 VP (variable pressure) scanning electron microscopy (SEM). The variable pressure SEM reduces surface charging of an organic sample by allowing a lowpressure atmosphere to pass over the sample to bleed off excess charge.

Particle size distributions were determined using the Saturn DigiSizer 5200 laser light scattering apparatus manufactured by Micromeritics Instrument Corporation. Samples of approximately $15 \mathrm{mg}$ of TATB in 2-ml DI water were dispersed with Coulter $1 \mathrm{~A}$ surfactant and 3 minutes of sonication in an external sonicator. The morphology of sulfolane recrystallized TATBs was evaluated using a Zeiss 40-A polarizing microscope under crossed polars with a first order red plate. Optical micrographs were calibrated against photographs of a stage micrometer at the same magnification with Axiovision software. Further description of the equipment used in the morphological studies can be found in the manufacturer instruction manuals. ${ }^{7,8,9}$

A Techne model DC-2 density gradient column was used for all crystal density measurements. The column was immersed in a water bath with temperature controlled to $23 \pm 0.05^{\circ} \mathrm{C}$. The manufacture claims density can be estimated to $0.0001 \mathrm{~g} / \mathrm{cc}$ with this equipment. ${ }^{10}$ The gradient was achieved using slow mixing 
of a high density aqueous $\mathrm{ZnBr}_{2}$ solution (approximately $2.00 \mathrm{~g} / \mathrm{cc}$ ) into a low density solution initially about $1.84 \mathrm{~g} / \mathrm{cc}$ which was fed into the gradient column. Calibrated glass density beads were added to the column and the height of the center of each bead was measured to within $0.1 \mathrm{~cm}$. A least squares calibration curve for the column was generated from the bead position and its density. Approximately 0.001 gram of TATB was immersed in the low density liquid to wet out the crystals and added to the top of the column with an eye dropper. The crystals were allowed to sink overnight to reach equilibrium density prior to counting. TATB particles within each gradation on the column were counted and the density calculated from the least squares fit of the calibration beads. Several thousand particles were counted in the gradient column. Further description of this apparatus and its application to explosive crystals is given elsewhere. ${ }^{11,12}$

Approximately 0.19 grams of TATB was compression molded using a Black Hawk press into $1.27 \mathrm{~cm}$ diameter disks approximately $0.08 \mathrm{~cm}$ high at pressures between $35-200 \mathrm{MPa}(5,000-30,000 \mathrm{psi})$ pressure at ambient for 1 minute and released. Pellet densities were calculated from dimensional measurements and weight. The surface of the pressed pellet was examined under epi illumination with differential interference contrast (DIC) inserts in the Zeiss 40-A polarizing microscope. ${ }^{9}$

\section{$\underline{\text { Results and Discussion }}$}

Small scale safety data 
Small scale safety data on the four different types of TATB are given in Table 1. A discussion of these safety tests has been presented elsewhere. ${ }^{5,6}$ As can be seen from the data, all of these explosives produce no reaction in impact, spark and friction tests. In Figure 1, the DSC traces of the new TATBs decompose at $10-15^{\circ} \mathrm{C}$ lower temperatures than the older TATBs. Wet aminated TATB has the highest decomposition peak temperature $\left(386.9^{\circ} \mathrm{C}\right)$, with an onset of about $353^{\circ} \mathrm{C}$. This synthetic route produces high purity TATB. ${ }^{13}$ Dry aminated TATB decomposed about $5-8^{\circ} \mathrm{C}$ lower $\left(378.3^{\circ} \mathrm{C}\right.$ peak temperature). It is known that $\mathrm{DA}$ TATB contains about $0.5 \%$ residual $\mathrm{NH}_{4} \mathrm{Cl}$ from the synthesis process. ${ }^{14-15}$ Scanning electron microscopy reveals micron size voids where this salt has been extracted from the crystal during washing, but it is currently unclear whether this or smaller size or impurities such as residual $\mathrm{NH}_{4} \mathrm{Cl}$ is responsible for the reduction in thermal decomposition temperature. The ATK sample had a second peak at about $352.7^{\circ} \mathrm{C}$ and the main decomposition peak at $368.4^{\circ} \mathrm{C}$. This is significantly lower than their reported peak temperature of $378.1^{\circ} \mathrm{C} .{ }^{5}$ Thiokol reports about $96 \%$ purity for their early TATB production which has been improved to $98 \%$ in more recent syntheses. BAE TATB reports purity of $98.5-$ $99.1 \%$ and decomposition peak temperatures of $364-368^{\circ} \mathrm{C}$, consistent with results given here. ${ }^{6}$ They also report $99.9 \%$ pure TATB synthesized at their Bridgewater plant in the UK had decomposition peaks between $389-381^{\circ} \mathrm{C}$, again consistent with our wet aminated result. We have found that ultrafine TATB produced by colloidal milling wet aminated TATB shows a reduction of about 5$7^{\circ} \mathrm{C}$ in the decomposition peak (around $379-380^{\circ} \mathrm{C}$ ), not enough to account for 
the $20^{\circ} \mathrm{C}$ reduction in the new BAE TATB. Although several kinetic studies of TATB with DSC ${ }^{16-18}$ have tried to estimate activation energies for thermal decomposition, they contain sparse information on the effects of particle size or impurities. It would appear that there is a relationship between purity, particle size and decomposition temperature, but further study would be required to determine what it is. The effect of particle size on thermal decomposition has also been seen in recent one dimensional time to explosion (ODTX) tests. ${ }^{19}$ Morphologies of TATBs

TATB morphologies were evaluated by scanning electron microscopy (SEM). As can be seen in Figure 2, SEM's of the various TATB's have very different morphologies. Both new TATBs in Fig. $2 b$ and $d$ are spherical aggregates. The ATK TATB large aggregates in Fig $2 \mathrm{~b}$ averaged about $77 \pm 16 \mu \mathrm{m}$ and were made up of smaller spherical particles about $28 \pm 8 \mu \mathrm{m}$ which are in turn made up of smaller crystalline aggregates of about $3 \pm 3 \mu \mathrm{m}$. BAE TATB in Fig $2 \mathrm{~d}$ was much finer, but also composed of spherical aggregates about $5 \mu \mathrm{m}$ across composed of submicron particles of about $0.7 \pm 0.3 \mu \mathrm{m}$. In Fig. 2a, WA TATB shows its characteristic polycrystalline structure, with crystallite sizes near 30-60 $\mu \mathrm{m}$, along with fines on the order of 5-10 $\mu \mathrm{m}$. Facets are often observed and steps on the surface have been seen in WA TATB. The classic DA TATB morphology is shown in Figure 2c. ${ }^{20,21}$ Facets of the triclinic unit cell can be seen peppered with holes where the ammonium chloride has been extracted during the last washing cycle. 


\section{Density distributions of TATBs}

Densities of TATB were measured using the density gradient technique. ${ }^{22-24}$ Theoretical maximum density (TMD) of TATB is $1.937 \mathrm{~g} / \mathrm{cc}^{25}$ Density distributions of dry and wet aminated TATB in Figure 3 were almost identical with the mean density of wet aminated being $1.9173 \mathrm{~g} / \mathrm{cc}$ or about $98.98 \% \mathrm{TMD}$ and dry aminated mean density of $1.9181 \mathrm{~g} / \mathrm{cc}$ or about $99.02 \% \mathrm{TMD}$. It is known ${ }^{1}$ that dry aminated TATB contains approximately $0.5 \%$ ammonium chloride from its synthesis route compared to about $0.1 \%$ for wet. Since the density of ammonium chloride is about 1.53 , the void volume of dry aminated TATB may be higher than the simplistic estimate given here. Looking at the SEM micrograph of dry aminated TATB in Figure $2 \mathrm{c}$ would seem to indicate that the 1-2 $\mu \mathrm{m}$ holes which cover the surface of the dry aminated crystals can be wetted and penetrated by the density gradient fluid. Assuming all the voids to be air would imply a void content of about $1 \%$. The Thiokol TATB density distribution maintained the shape of the wet and dry aminated distributions, but was shifted to lower density. This may imply that the mechanism of void formation is similar in these 3 samples. The average density $(1.8355 \mathrm{~g} / \mathrm{cc}$ or only $94.75 \% \mathrm{TMD})$ was much lower than the legacy TATBs. It is known that ATK and BAE TATBs contain on the order of $2 \%$ impurities. $^{2,3}$ Although the density of these impurities is not known, it is expected to be comparable or higher than ammonium chloride. Again the estimate of percent voids would probably be higher than the simple difference approximation (5.3\%). The very fine BAE particle size made the density distribution difficult to measure. As can be seen in Figure 3, a very broad 
distribution was found for this TATB with a mean density of $1.8010 \mathrm{~g} / \mathrm{cc}$. Near $1.91 \mathrm{~g} / \mathrm{cc}$ density a group of large particles was observed, above this density until about $1.78 \mathrm{~g} / \mathrm{cc}$ fine particles increased in number and below $1.78 \mathrm{~g} / \mathrm{cc}$ a cloud of very fine particles was observed up to nearly the top of the column $(1.765 \mathrm{~g} / \mathrm{cc})$. The number of particles in the cloud was estimated by counting a region and assuming similar regions contained similar number of particles.

\section{$\underline{\text { Particle size distributions }}$}

Light scattering measurements of particle size distribution showed the new TATB's have more fines than WA or DA as shown in Figure 4. The samples of BAE TATB were finer than UF by almost a factor of 2 , cf, $2.2 \mu \mathrm{m}$ compared to 3.8 $\mu \mathrm{m}$ average diameter for ultrafine TATB ground in a Sturtevant micronizer. ${ }^{26,27}$ Perhaps the spherical aggregates of ATK break down during sonication to produce the extra fines, but the mean particle size was $56 \mu \mathrm{m}$, only slightly smaller than B-090 dry aminated TATB $(70 \mu \mathrm{m})$. Wet aminated TATB had an average particle size of approximately $48 \mu \mathrm{m}$. So although the morphology is drastically different, ATK is a reasonable particle size match for current stockpile TATB's. BAE claims to have the ability to produce multiple sizes ${ }^{2}$, similar to the classes of HMX and RDX but the sample obtained from NAWS at China Lake was very fine and might light better than UF. The relative frequencies of the distributions for ultrafine and BAE TATBs in Figure 5 clearly show the bimodal nature of these materials.

Characterization of sub-micron structure: 
Ultra small angle $x$-ray scattering (USAXS) probes structures from $\sim 10 \mathrm{~nm}$ to $\sim 2$ microns. ${ }^{28}$ Figure 6 presents USAXS from wet-aminated (WA), dry aminated (DA), Holsten (BAE) and Thiokol (ATK) TATB from small disks pressed at 30,000 psi. Although pressed samples presented here and, to a greater extent, the powders showed multiple scattering, qualitatively the data shows a number of interesting characteristics. Scattering occurs due to electron density differences, and thus cannot distinguish between scattering from particles or voids. In these cases, the calculated volume contributing to the scattering calculated using the invariant ${ }^{29}$ is about $5 \%$ and $4 \%$ for wet and dry aminated, $13 \%$ for the Holsten and $4 \%$ for the Thiokol TATB. With the exception of the Thiokol, these are much higher than the void volume calculated by density, so we must assume the observed scattering occurs from both voids and particles.

The Holsten and Thiokol samples have a much larger population of small scatterers (less than $\sim 50 \mathrm{~nm}$ ) than the wet- and dry- aminated as seen by the more intense scattering intensity at high scattering angle (larger than about $10^{-2}$ / $\AA$ ). For the Holsten TATB, this is consistent with the smaller crystallites seen in the SEM micrographs of Figure 2d. The surface-area-to-volume ratio calculated from the USAXS is also about one order of magnitude larger in both the Holsten and Thiokol compared to the wet- and dry-aminated TATB.

The clearest scattering difference between the Thiokol and the other TATB samples is the power-law exponent annotated in Fig. 6. For an ideal, two phase 
system (i.e. TATB and air) with three-dimensional scatterers, the exponent approaches $-4 .{ }^{29,} 30$ Wet-aminated $(-3.89$ to -3.94$)$ dry-aminated $(-3.85$ to -3.90$)$ and even the Holsten (-3.97) are very close to this value, indicating an abrupt interface between TATB and air, consistent with crystalline facets at the interface. Thiokol TATB, however, has an exponent of -3.42. Although different power-law exponents are associated with reduced dimensionality, the exponent seen in the Thiokol case most likely arises from a diffuse or rough fractal-like surface interface. $^{29}$

\section{Pressing characteristics}

The density, $\rho$, of $\sim 0.2 \mathrm{~g}$ disks of TATB was evaluated as a function of pressing pressure, $\mathrm{P}$, between $35<\mathrm{P}<210 \mathrm{MPa}(5,000$ to $30,000 \mathrm{psi})$ for a single, one minute dwell at ambient. For zero pressure the bulk density of the sample was used. As molding pressure is increased, the part density should approach the theoretical maximum for the density, $\rho_{\mathrm{T}}$, of the TATB crystal $(1.937 \mathrm{~g} / \mathrm{cc})$. The percentage of $\rho_{\mathrm{T}}$ is:

$$
\% \mathrm{TMD}=100 \rho / \rho_{\mathrm{T}}
$$

Assuming only air is trapped internally and its contribution to the density is negligible, the void volume fraction, $\phi(v)$, would be $1-\rho / \rho_{T}$. A schematic diagram of the process is shown as an insert in Figure 7 . The part density as a function of ram pressure for a single 1 minute dwell was highest at $200 \mathrm{MPa}$ (30 ksi) in all 
cases. WA and DA TATB could be pressed to nearly theoretical maximum density (TMD), 99.3 and $99.7 \%$, respectively. ATK TATB could be pressed only to $94.9 \%$ TMD and the fine powder BAE TATB would only press to $90.9 \%$. This may be due to the spherical structure of these TATBs and the smaller particle size of BAE. Ultrafine TATB (ground) also does not press to very high density. ${ }^{24}$ Table 2 lists the densities and void volume fraction of the different TATBs.

Each pressed pellet surface was examined in reflection using Differential Interference Contrast (DIC) microscopy. In some instances it is possible to distinguish inter-crystalline interfaces due to differences in refractive indices between crystals. ${ }^{31-33}$ Photomicrographs, shown in Figure 8, were taken at the highest magnification $(\sim 1000 \mathrm{x})$ and the $20 \mu \mathrm{m}$ bar in the lower left micrograph is representative for all photos. At the highest pressures, usually TATB crystals are no longer identifiable due to surface damage and flow. At lower pressures an attempt was made to measure crystal dimensions where such structures were observable.

In Figure 7, the density dependence of wet aminated TATB with increasing molding pressure was sigmoidal. The DIC micrographs of the pressed pellet at low pressure, first row first column in Figure 8, show a rough interface. Since the depth of field is low, out of focus regions at low pressure represent depressions or high spots on the surface. The area of the out of focus parts of the first micrograph in Figure 8 (35 MPa) under WA consists of about $12 \%$. This is not 
very close to the $24 \%$ voids estimated from the density difference at this pressure. This would seem to imply that the defects are mainly interstitial crystal packing problems and are fairly large at low mold pressures. At higher pressures plastic deformation allows the polycrystalline aggregates in WA TATB to deform and fill the interstitial voids. The WA crystals on the surface begin to coalesce at about $140 \mathrm{MPa}$ (15 ksi). Prior to coalescence, particle size on the surface does not seem to change significantly running between $15<$ dia. $<35 \mu \mathrm{m}$. This is about $25 \%$ smaller that the average particle size of the unpressed WA TATB consistent with crystalline fracture and particle size reduction observed in compression molded PBXs. ${ }^{34}$

In Figure 7, the density dependence of dry aminated (DA) TATB with molding pressure increased asymptotically toward TMD. Judging by the density, the larger crystals of DA TATB packed better than WA TATB at lower pressure although in the high pressure limit the densities were indistinguishable (1.933 and 1.924 for DA and WA TATB respectively). These DA crystals withstood the pressure better than WA based on nearly constant crystal dimensions with increasing pressure (compare Fig 8, column 1 with column 2). Some of the DIC images at low molding pressure showed voids on crystal faces parallel to the surface which were on the order of $1-3 \mu \mathrm{m}$ similar in size to the voids observed in the DA TATB SEM in Figure 2c. The out of focus surface area of DA TATB pressed at $35 \mathrm{MPa}, 12.6 \%$, compared well with $16 \%$ void volume based on density measurements. 
The BAE TATB has very low bulk density $(0.472 \mathrm{~g} / \mathrm{cc})$ compared to all of the other TATBs ( 0.8 to $0.9 \mathrm{~g} / \mathrm{cc}$ ). The pressing characteristics are shown in Figure 7. Low pressure increased the density by $3 x$ but with increasing pressure only 91\% TMD was obtained, the lowest of all pressed pellets. The small particles of the original BAE TATB sample are only observed in DIC micrographs of the disk surface at the lowest pressure (see Figure 8 column 3). Above $35 \mathrm{MPa}(5 \mathrm{ksi})$ only the marks of the ram surface and large aggregates of unknown origin were observed. These aggregates are not seen at all pressures, but could be found in different regions of the surface above $35 \mathrm{MPa}(5 \mathrm{ksi})$. Comparison of the surface to volume void content for BAE TATB was not possible because of the small size of the TATB particles. This material cannot be the so called "dirty binder", ${ }^{35,36}$ since no binder was used to prepare these samples and the idea of rubbelized particles being generated seems less likely with these fine particles. With pressure, as expected, these small primary particles seemed to compact well, compared to substantial plastic flow in the TATBs with larger crystals at higher pressures. Densities, unfortunately, do not improve beyond $91 \%$ at maximum pressure.

Pressing characteristics of ATK TATB are similar to WA as shown in Figure 7. The spherical particles seen in the SEM in Figure $2 \mathrm{c}$ are also evident on the pellet surface at low to moderate molding pressure in Figure 8. At about $20 \mathrm{ksi}$, the marks of the ram surface are seen in the pellet. The internal structures of the 
spherical particles appear as the pressure increased. Estimating the out of focus area gave $17.3 \%$ compared to density void volume of $17.0 \%$, the best comparison of all samples.

Improved thermal stability by recrystallization.

The thermal stability and the density distribution of these new TATBs can be improved significantly by rapid recrystallization in sulfolane. Previous attempts at improving crystal quality have used a variety of solvents including dimethyl sulfoxide, diphenyl ether, solfolane ${ }^{37,38}$ nitrobenzene ${ }^{25}, 1,2$ dichlorobenzene, benzonitrile, dimethyl formamide and chlorobenzene. ${ }^{39}$ Recently in an attempt to make fine TATB particles superacids methane and ethane sulfonic acid and hexamethylphosportriamide were found to dissolve TATB. ${ }^{40}$ Sulfolane was selected because of its relatively rapid dissolution of TATB at $190^{\circ} \mathrm{C}$ and sharp and rapid precipitation characteristics on lowering the temperature to $175^{\circ} \mathrm{C}$. Also a high degree of recovery of TATB was observed for crystallization under these conditions. The new TATB was suspended in sulfolane $(1.2 \% \mathrm{w} / \mathrm{v})$ and rapidly heated with stirring for 4 min when dissolution occurred $\left(\sim 190{ }^{\circ} \mathrm{C}\right)$. The heat source was removed and the resulting solution cooled and stirred with crystallization commencing at $\sim 175^{\circ} \mathrm{C}$. The crystalline suspension was stirred (30 min) and then filtered $\left(\sim 30^{\circ} \mathrm{C}\right)$. The recrystallized TATB was washed with 
acetone, water and acetone and dried under vacuum. Yellow, crystalline TATB recoveries varying from 89 to $100 \%$ have been obtained.

Polarized optical micrographs of the sulfolane recrystallized TATB from the BAE sample are shown in Figure 9. These large, triclinic crystals averaged $83 \pm 17$ $\mu \mathrm{m}$ normal to the [001] axis and many contained what appear to be etch pits or inclusions about $3.4 \pm 0.6 \mu \mathrm{m}$ across. It would seem that one of the BAE impurities from their synthesis route tends to act as a nucleating agent and remain included in the crystal. The peak decomposition temperature in the DSC for these crystals in Figure 11 increased by $13^{\circ} \mathrm{C}$ compared to the original $\mathrm{BAE}$ TATB in Figure 2. The bimodal character of the exotherm is often observed in TATB ${ }^{17}$ and has been attributed to an autocatalytic first step in the decomposition of TATB, but may reflect the influence of impurities on the thermal decomposition.

The ATK recrystallized crystals in Figure 10 averaged $120 \pm 40 \mu \mathrm{m}$ with lower levels of inclusions than were found in the BAE crystals and what appear to be dislocations in nicely formed triclinic crystals. Again the DSC decomposition temperature increased after recrystallization. In this case, the decomposition peak was $0.6^{\circ} \mathrm{C}$ higher than the legacy WA sample, also shown in the figure. Further optimization of a short residence time recrystallization procedure would seem to be of interest since it seems to lend itself to scale up, but was not 
pursued here. Average density of the recrystallized ATK TATB increased from

$1.835 \mathrm{~g} / \mathrm{cc}$ to $1.9140 \mathrm{~g} / \mathrm{cc}$, comparable to wet and dry aminated densities.

\section{$\underline{\text { Conclusions }}$}

Significant differences between new and legacy TATBs were found in this study. Although the particle size distribution as measured by light scattering for WA, DA and ATK TATBs was similar, the morphology, thermal stability, density, and submicron structure were significantly different. BAE TATB had much smaller particles than the legacy TATBs. How this will affect the formulation and performance of DOE plastic bonded explosives (PBXs) such as LX-17 and PBX 9502 prepared from new TATBs compared to legacy material is currently under study, but results are not expected to be similar to the extensive data on current PBXs. Different morphologies and surface characteristics are expected to alter processing characteristics in the Holston slurry coating reactor. Molding powder

size, bulk density, and granularity may be affected. Pressing characteristics and mechanical properties are expected to change. Lower densities of the new TATBs are expected to alter initiation characteristics, probably making the PBXs easier to initiate. Reduced thermal stability may alter cook off characteristics. Experiments are ongoing or planned to address some of these questions.

\section{Acknowledgements}


We would like to thank Tim Mahoney at China Lake for supplying the new TATB samples. George Overturf, John C. Estill, and Bill Mclean provided funding for this work in conjunction with engineering efforts of Peter Raboin and Angela Cook. Pat Lewis ran the light scattering measurements for particle size distributions. Heidi Turner made the thermal analysis measurements. Aaron Fontes made the density distribution measurements. We acknowledge Lisa Lauderbach and Tony van Buuren of LLNL, and Jan llavsky, Advanced Photon Source, Argonne National Laboratory for assistance in performing USAXS experiments. Use of the Advanced Photon Source was supported by the U. S. Department of Energy, Office of Science, Office of Basic Energy Sciences, under Contract No. DE-AC02-06CH11357.

\section{Disclaimer}

This document was prepared as an account of work sponsored by an agency of the United States government. Neither the United States government nor Lawrence Livermore National Security, LLC, nor any of their employees makes any warranty, expressed or implied, or assumes any legal liability or responsibility for the accuracy, completeness, or usefulness of any information, apparatus, product, or process disclosed, or represents that its use would not infringe privately owned rights. Reference herein to any specific commercial product, process, or service by trade name, trademark, manufacturer, or otherwise does not necessarily constitute or imply its endorsement, 
recommendation, or favoring by the United States government or Lawrence Livermore National Security, LLC. The views and opinions of authors expressed herein do not necessarily state or reflect those of the United States government or Lawrence Livermore National Security, LLC, and shall not be used for advertising or product endorsement purposes

\section{$\underline{\text { References }}$}

1. J.C. Colville, "LX-17 and LX-10 Test Data" SR-92-03 (June 9, 1992) Pantex Plant.

2. B. Sleadd, "Synthesis and Scale-up of sym-triaminotrinitrobenzene at Holston Army Ammunition Plant, 2006 IM\&EM Technology Symposium, Bristol, UK.

3. S. Velarde, "Pilot Plant Synthesis of Triaminotrinitrobenzene (TATB)" 2006 IM\&EM Technology Symposium, Bristol, UK.

4. T. Mahoney, Naval Air Warfare Center, China Lake, CA. Private communication, (2006)

5. A. M. Mellor, T. L. B., J. Covino, C.W. Dickenson, D. Dreitzler, L. B. Thorn, R. B. Frey, P.W. Gibson, W. E. Roe, M. Kirshenbaum and D. M. Mann (1988). "Hazard Initiation in Solid Rocket and Gun Propellants and Explosives." Prog. Energy Combust. Sci. 14: 213

6. L.R. Simpson and M.F. Foltz, "LLNL Small-Scale Friction Sensitivity (BAM) Test”, UCRL-ID-124563 (June 1996); "LLNL Small-Scale Drop-Hammer Impact Sensitivity Test, UCRL-ID-119665, (January 1995). “LLNL Small-Scale Static 
Spark Machine: Static Spark Sensitivity Test", UCRL-ID-135525 (Aug. 1999).

Lawrence Livermore Laboratory, Livermore, CA

7. LEO 435VP Operators Manual version 3.0, Leo Electron Microscopy, Ltd. Cambridge, England (May, 1997).

8. Saturn DigiSizer 5200 Operators Manual 520-42801-01, Micromeritics Instrument Corporation, Norcross, GA (Aug. 2002).

9. Zeiss Axioskop 40 Pol Polarizing Microscope Operating Manual B 46-0016, Carl Zeiss Light Microscopy, Goettingen, Germany (Oct. 1, 2002).

10. Techne Operating Manual, Techne, Inc., 10 Brunswick Pike, Princeton, NJ, DC-1, DC-2, DC-3 and DC-4 (Feb. 1988).

11. D. M. Hoffman, "Voids and Density Distributions in 2,4,6,8,10,12-Hexanitro2,4,6,8,10,12-Hexaazaisowurtzitane (CL-20) Prepared Under Various Conditions." Propellants, Explosives, Pyrotechnics 28( 4) (2003).

12. Hoffman, D. M. (2001). "Density Distributions in Cyclotrimethylenetrinitramines (RDX) " $38^{\text {th }}$ JANNAF Meeting, Destin, FI. 2002 (UCRL-JC-147684 March 19, 2002)

13. T. M. Benziger, "Method for the Production of High-Purity Triaminotrinitro benzene." U. S. Patent No. 4,032,377 (June 1977)

14. A.J. Bellamy, S. J. Ward and P. Golding, "A New Synthetic Route to 1,3,5triamino-2,4,6-trinitrobenzene (TATB) Propellants, Explosives, Pyrotechnics, 27, 49-58 (2002).

15. D. G. Ott and T. M. Benziger. "Preparation of 1,3,5-triamino-2,4,6trlnItrobenzene From 3,5-Dichloroanisole" J. Energetic Mats., 5, 343-354 (1987). 
16. R.N. Rogers, J.L. Janney and M.H. Ebinger, "Kinetic-Isotope Effects in Thermal Explosions", Thermochimica Acta, 59 (1982) 287-298.

17. E. Catalano and P.C. Crawford, "An Enthalpic Study of the Thermal Decomposition of Unconfined TATB", Thermochimica Acta, 61 (1983) 23-36.

18. S. Zeman, The Thermoanalytical Study of some Aminoderivatives of 1,3,5trinitrobenzene", Thermochimica Acta, 216 (1993) 157-168.

19. J. Koerner, J. Maienschein, A. Burnham, and A. Wemhoff, MS "ODTX Measurements and Simulations on Ultra Fine TATB and PBX 9502" (2007). 20. H. H. Cady, "Microstructural Differences in TATB that result from manufacturing Techniques" $9^{\text {th }}$ Det Symposium 53-1-16 (1987).

21. A. A. Duncan "TATB Powder Characteristics of Holston-Formulated PBX 9502", MHSMP-91-18, Mason \& Hanger Pantex Plant (May 1991).

22. B. W. Low and F. M. Richards, "The Use of the Gradient Tube for the Determination of Crystal Densities," J. Am. Chem. Soc., 74, 1660 (1952).

23. L. H. Tung and W.C. Taylor, J. Polym Sci., 21, 144 (1956).

24. ASTM D 1505-85 "Standard Test Method for Density of Plastics by the Density-Gradient Technique".

25. H. H. Cady and A.C. Larson, Acta Cryst., 18, 485 (1965).

26. D.M. Chambers, "Analysis of UF TATB by Ultrasonic Equilibrium head Space Analysis", UCRL-ID-140673, Lawrence Livermore Labs, Livermore, CA (2000).

27. H. Golopol, “Ultrafine TATB Aging Study”, UCRL-88018, Lawrence Livermore Labs, Livermore, CA 94550 (Oct. 1982). 
28. J. llavsky, P. Jemian, A. J. Allen, and G. G. Long, "Versatile USAXS (BonseHart) Facility for Advanced Materials Research," Synchrotron Radiation Instrumentation: Eighth International Conference, edited by T. Warwick et al., 2004, pgs. 510-513.

29. R-J Roe, "Methods of X-ray and Neutron Scattering in Polymer Science," Oxford University Press, 2000.

30. T.M. Willey, T. van Buuren, J.R.I. Lee, G.E. Overture, J.H. Kinney, J. Handly, B.L. Weeks, and J. llavsky, "Changes in Pore Size Distribution upon Thermal Cycling of TATB-based Explosives Measured by Ultra-Small Angle X-ray Scattering", Propellants, Explosives, Pyrotechnics, 31(6) 466 (2006)

31. R. Danz, P. Gretscher, "C-DIC: a new microscopy method for rational study of phase structures in incident light arrangement", Thin Solid Films, 462-463, 267-262 (2005).

32. G. Sazaki, K. Tsukamoto, S. Yai, M. Okada and K. Nakajima, "In Situ Observation of Dislocations in Protein Crystals during Growth by Advanced Optical Microscopy" Cryst. Growth Design, 5, 1729-1735 (2005).

33. A.P.R. Johnston, A.N.Zelikin, L. Lee and F. Caruso, "Approaches to Quantifying and Visualizing Polyelectrolyte Multilayer Film Formation on Particles", Anal. Chem., 78, 5913-5919 (2006).

34. A. Duncan, Powder Characterization Seminar Notes, BWXT Pantex, Amarillo, TX (Sept. 15, 2003) 
35. P.D. Peterson \& D. J. Idar, "Microstructural Differences between Virgin and Recycled Lots of PBX 9502", Propellants, Explosives, Pyrotechnics, 30(2) 88 (2005).

36. C.B. Skidmore, D.S. Phillips and N.B. Crane, "Microscopical Examination of Plastic Bonded Explosives", Microscope, 45(4) 127-136 (1997).

37. M. F. Foltz, J. L. Maienschein, L.G. Green. "Particle size control of 1,3,5triamino-2,4,6-trinitrobenzene by recrystallization from DMSO." Journal of Materials Science, 31(7): 1741-1750. (1996).

38. Foltz, M. F., D. L. Ornellas, P.F. Pagoria and A.R. Mitchell. (1996). "Recrystallization and solubility of 1,3,5-triamino-2,4,6-trinitrobenzene in dime9thyl sulfoxide." Journal of Materials Science, 31(7): 1893-1901.

39. A. R. Mitchell unpublished results (2006)

40. Talawar, M. B., A. P. Agarwal, et al. "Method for preparation of fine TATB (2$5 \mathrm{mu} \mathrm{m}$ ) and its evaluation in plastic bonded explosive (PBX) formulations." Journal of Hazardous Materials, 137(3): 1848-1852 (2006). 


\section{$\underline{\text { Tables }}$}

Table 1. Small scale safety test results show all synthetic routes produce insensitive HE.

\begin{tabular}{llllll}
\hline TATB & DH 50 & Friction & Spark & DSC (Ton) & Tpk \\
WA & $>177.4 \mathrm{~cm}$ & $>36.0 \mathrm{Kg}$ & $\mathrm{NS}$ & 353 & 386.9 \\
DA & $>177.4 \mathrm{~cm}$ & $>36.0 \mathrm{Kg}$ & $\mathrm{NS}$ & 348 & 378.3 \\
ATK & $>177.4 \mathrm{~cm}$ & $>36.0 \mathrm{Kg}$ & $\mathrm{NS}$ & 285 & $352.7 ; 368.4$ \\
BAE & $>177.4 \mathrm{~cm}$ & $>36.0 \mathrm{Kg}$ & $\mathrm{NS}$ & 310 & 367.3 \\
\hline
\end{tabular}

Table 2. Density, $\rho$ and void volume, $\phi(v)$, of $0.2-g$ disks of TATB as a function of pressing pressure, $\mathrm{P}$.

\begin{tabular}{|c|c|c|c|c|c|c|c|c|}
\hline P \ TATB & $\rho(\mathrm{DA})$ & $\phi(\mathrm{v})$ & $\rho(\mathrm{WA})$ & $\phi(\mathrm{v})$ & $\rho(\mathrm{ATK})$ & $\phi(\mathrm{v})$ & $\rho(\mathrm{BAE})$ & $\phi(\mathrm{v})$ \\
\hline $0 \mathrm{MPa}$ & 0.973 & 50 & 0.773 & 60 & 0.968 & 50 & 0.472 & 76 \\
\hline 35.2 & 1.629 & 16 & 1.473 & 24 & 1.617 & 17 & 1.475 & 24 \\
\hline 66.9 & 1.799 & 7.1 & 1.524 & 21 & 1.662 & 14 & 1.634 & 16 \\
\hline 106.2 & 1.886 & 2.6 & 1.772 & 8.5 & 1.793 & 7.4 & 1.706 & 12 \\
\hline 137.2 & 1.888 & 2.5 & 1.824 & 5.8 & 1.832 & 5.4 & 1.743 & 10 \\
\hline 208.2 & 1.933 & 0.21 & 1.924 & 0.67 & 1.842 & 5.1 & 1.761 & 9.1 \\
\hline
\end{tabular}




\section{$\underline{\text { Figures }}$}

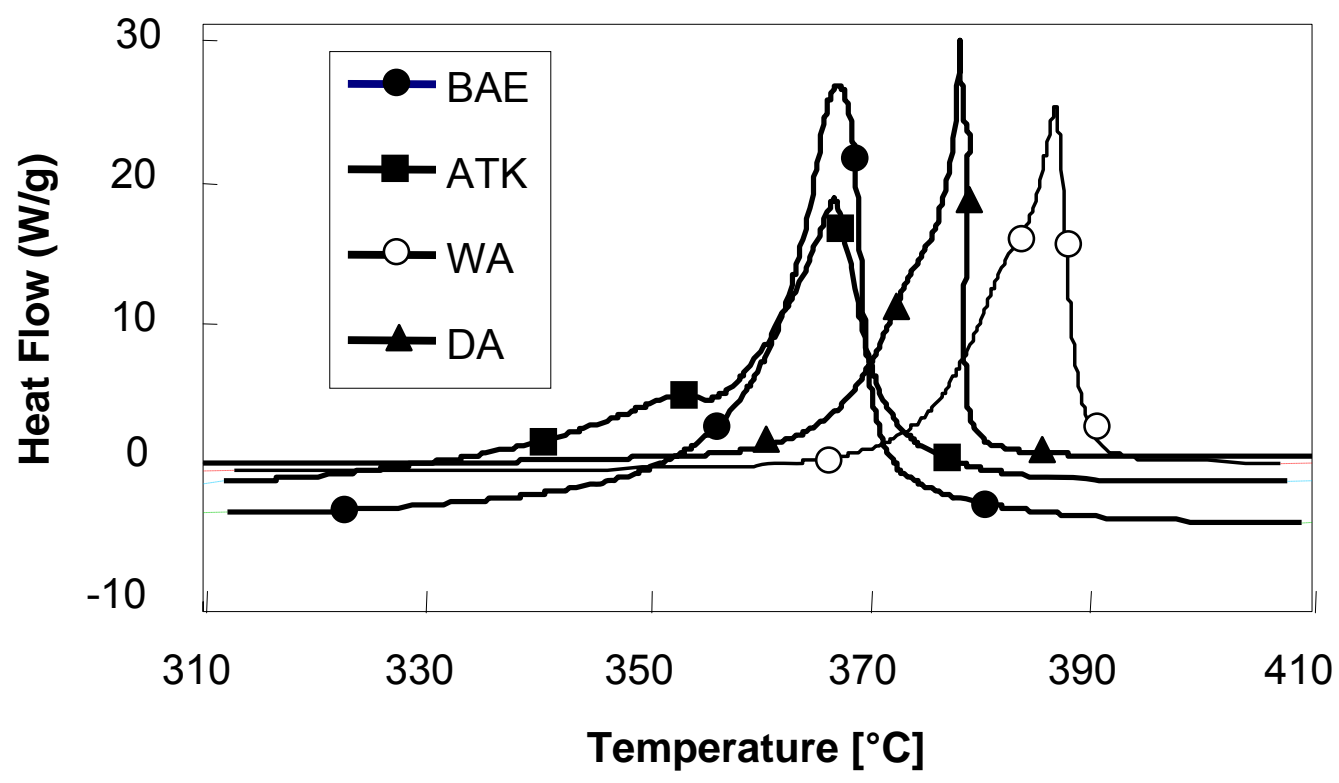

Figure 1. Differential scanning calorimetry (DSC) traces from the four synthetic routes show lower decomposition temperatures for the newer TATBs apparently due to impurities. 


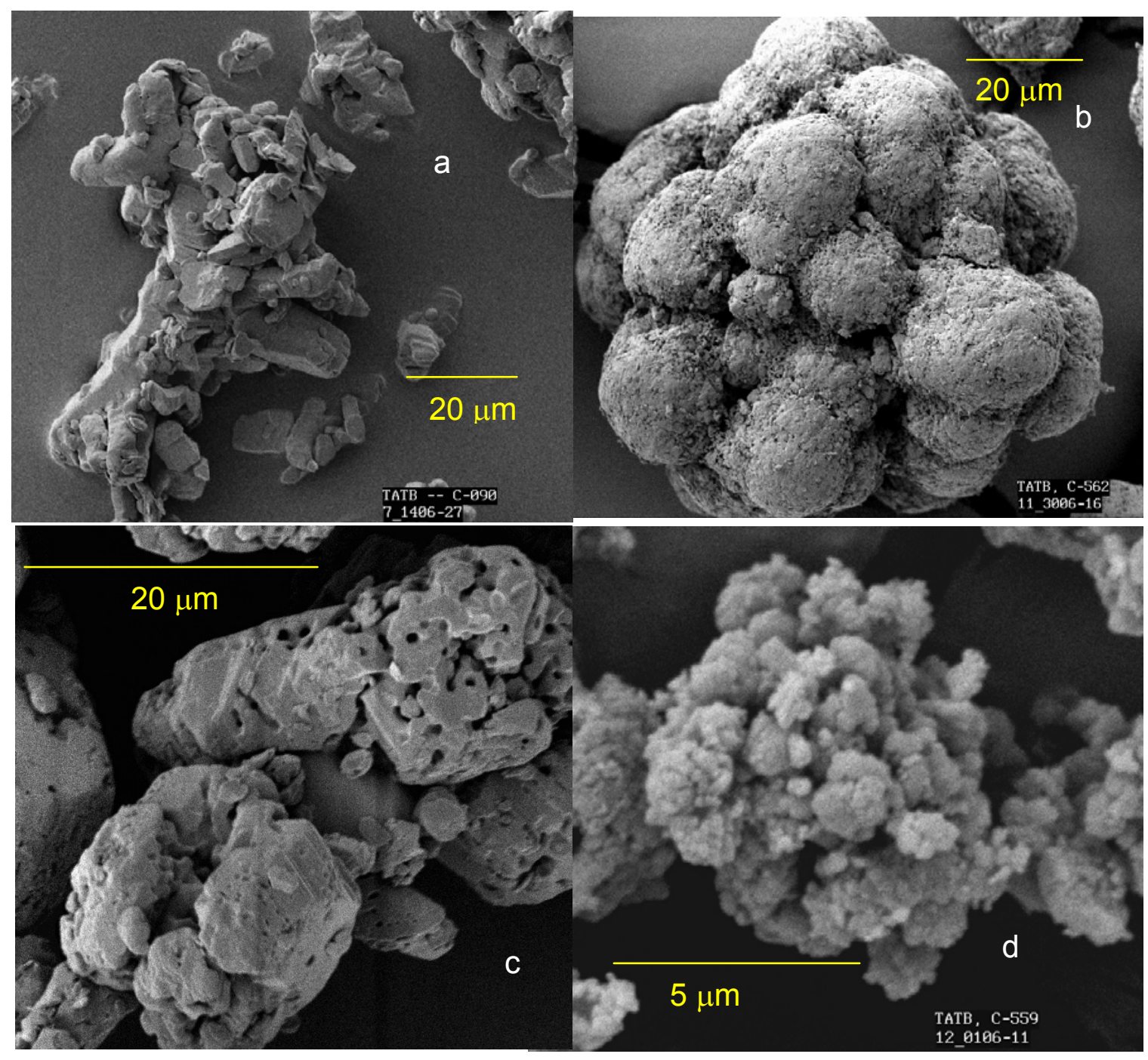

Figure 2. SEMs of (a)Wet aminated TATB; (b) ATK Thiokol TATB (c) Dry aminated TATB and (d) BAE Holston TATB. 


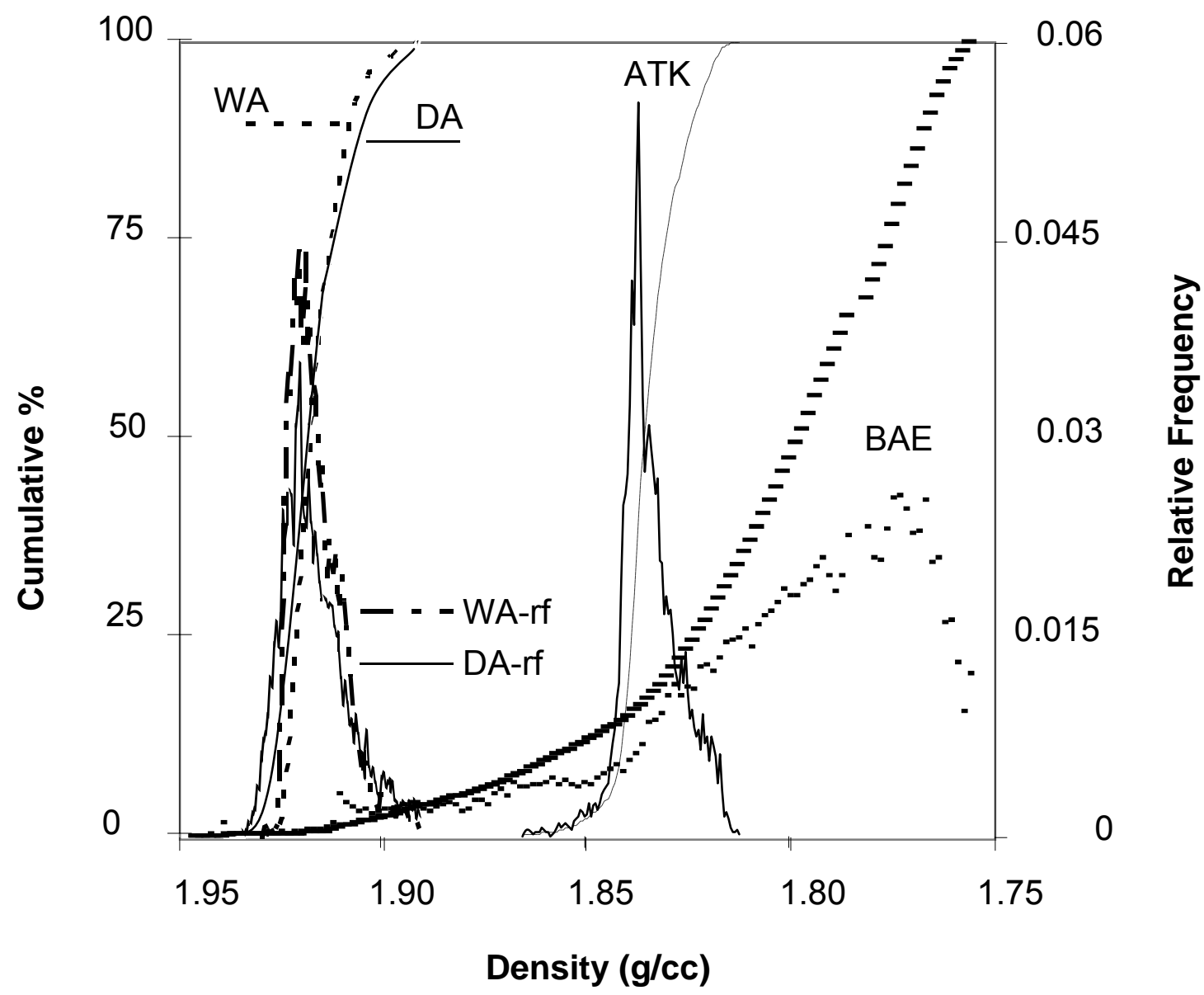

Figure 3. Density distributions in new TATB was much lower than in original wet and dry aminated TATB, probably due to impurities and voids. 


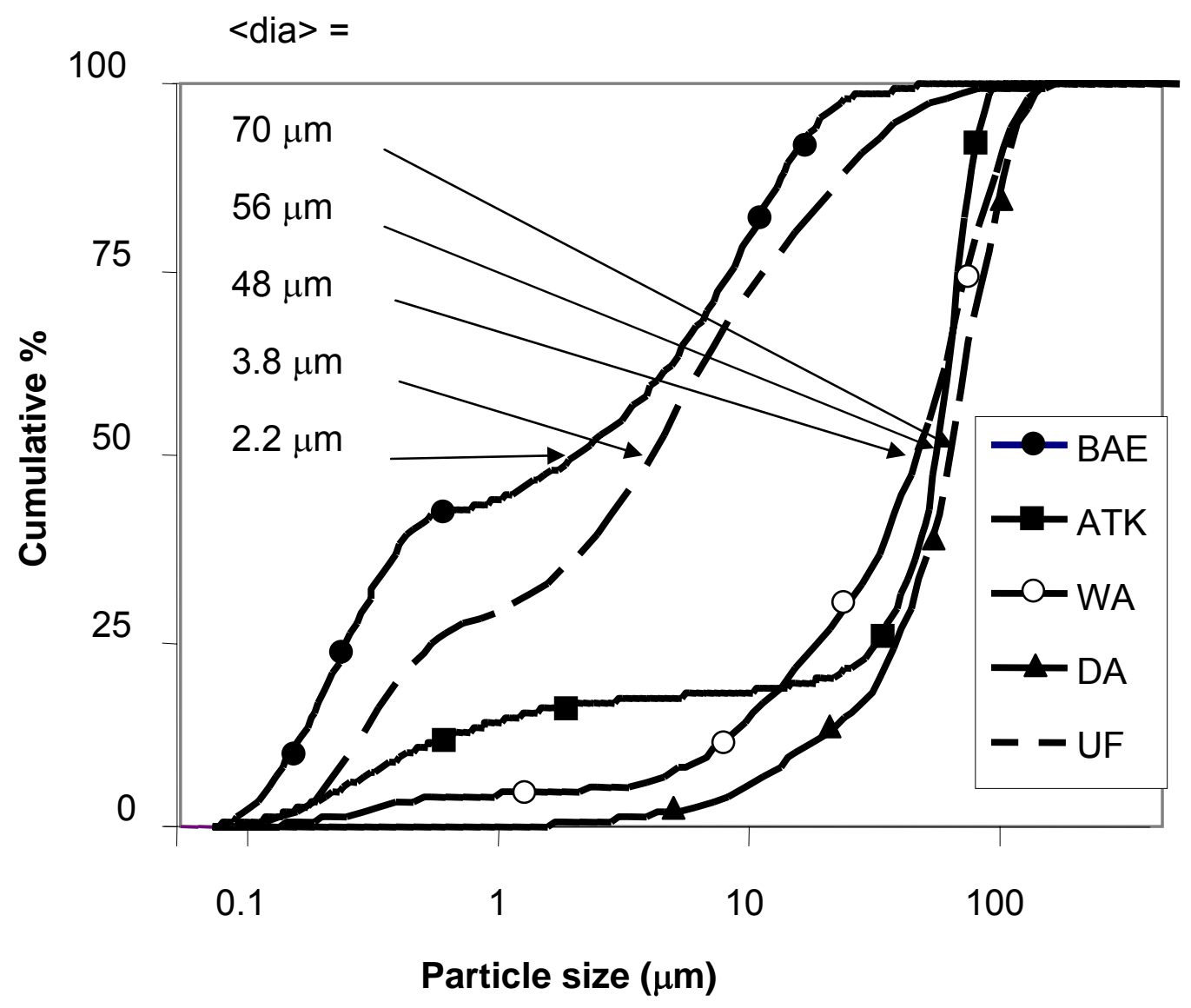

Figure 4. ATK, wet and dry aminated TATB particle size distribution were fairly similar, but BAE TATB was finer than ultrafine TATB made in a Sturtevant mill.

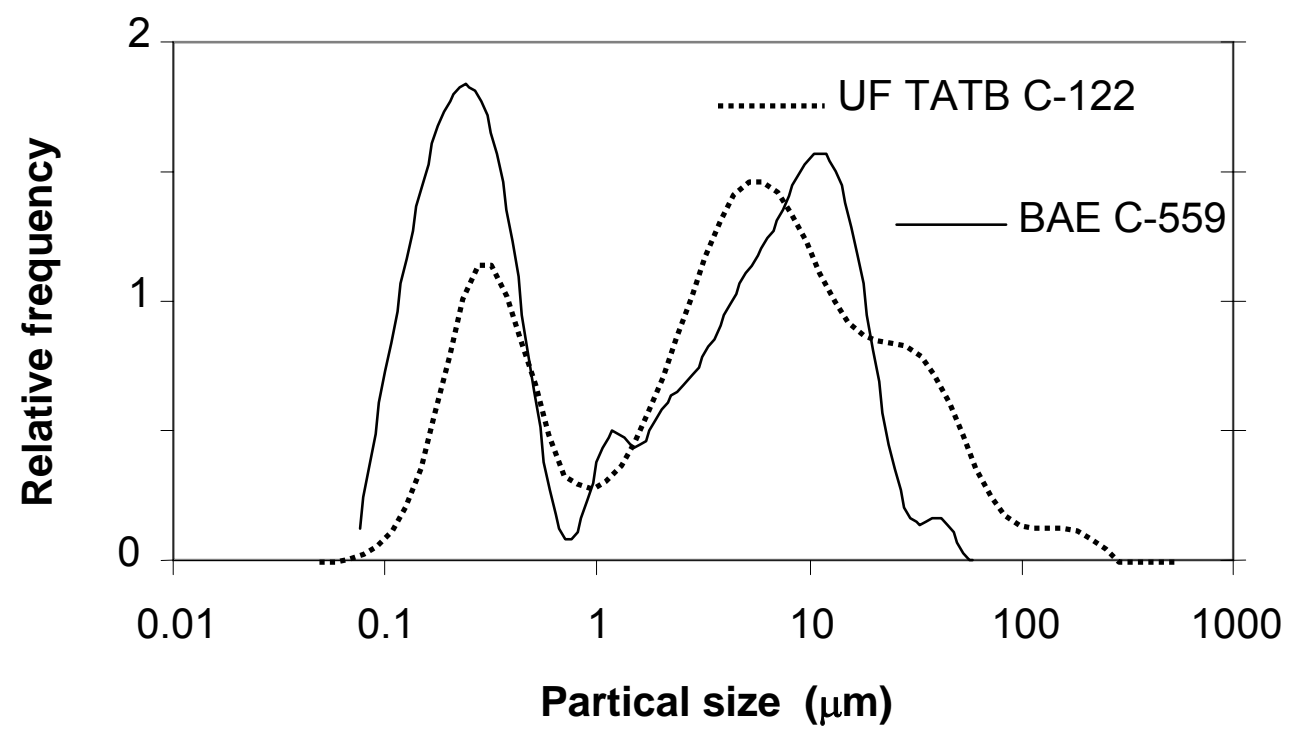

Figure 5. Relative frequency of particles of BAE and ultra fine TATB show the bimodal characteristics of these materials. 


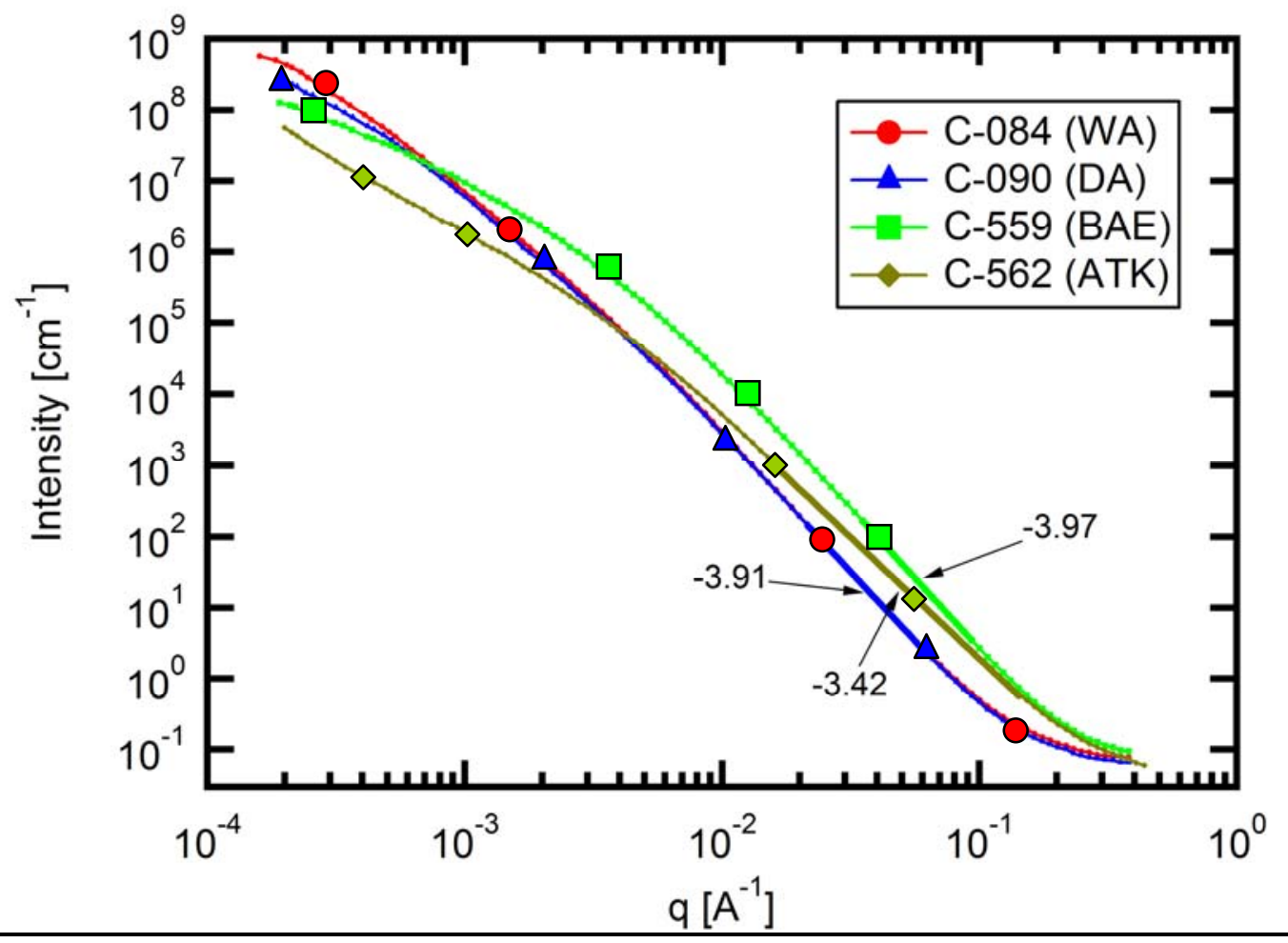

Figure 6. Comparison of ultra small angle x-ray scattering of WA (red), DA (blue), BAE (green) and ATK (yellow) TATBs from pressed disks shows substantial differences between manufacturers.

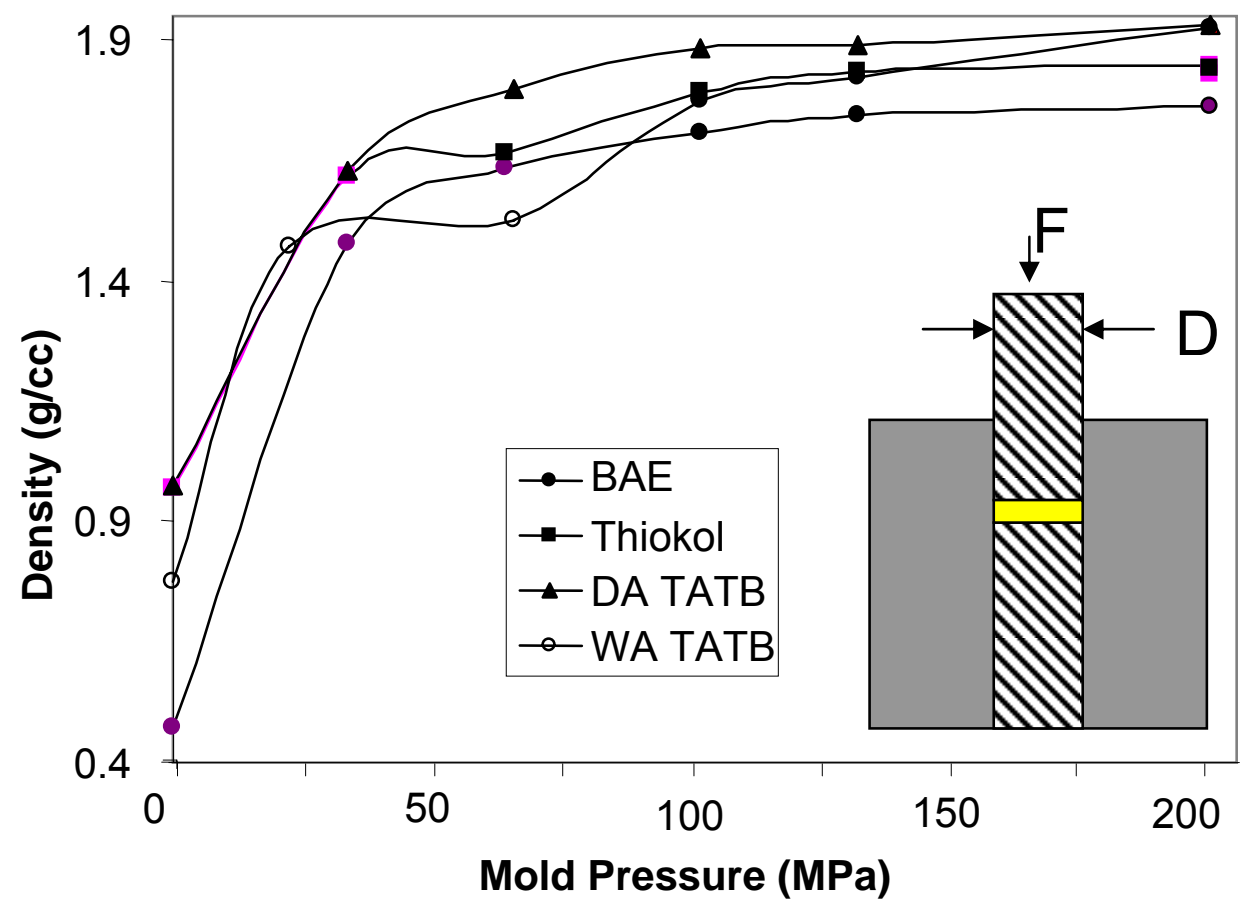

Figure 7. Density as a function of pressure for single dwell ambient pellet of TATB increased slowly as the pressure increased above 5000 psi. 

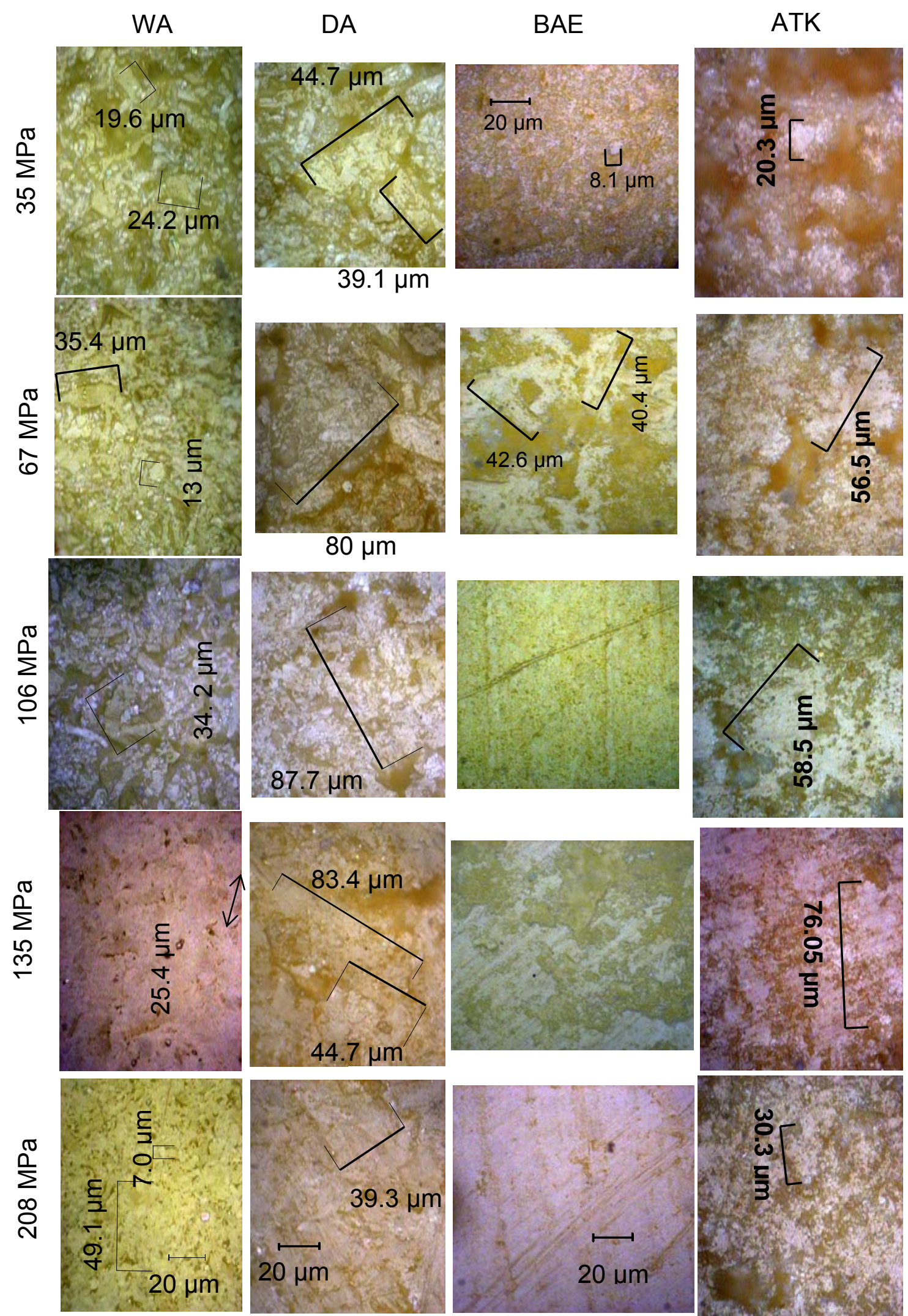

Figure 8. Differential interference contrast micrographs of the surfaces of the various TATBs show increasing plastic deformation with pressure. 


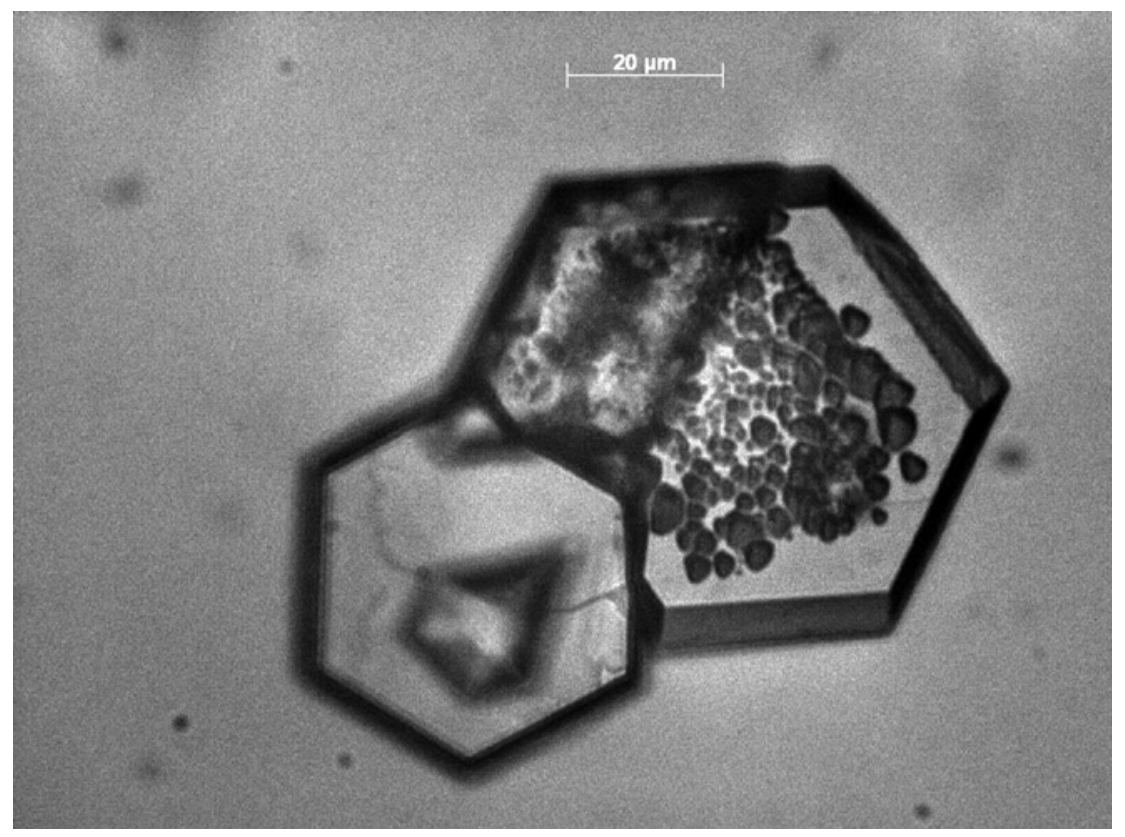

Figure 9. BAE TATB recrystallized in sulfolane showed etch pits or inclusions in many crystals.

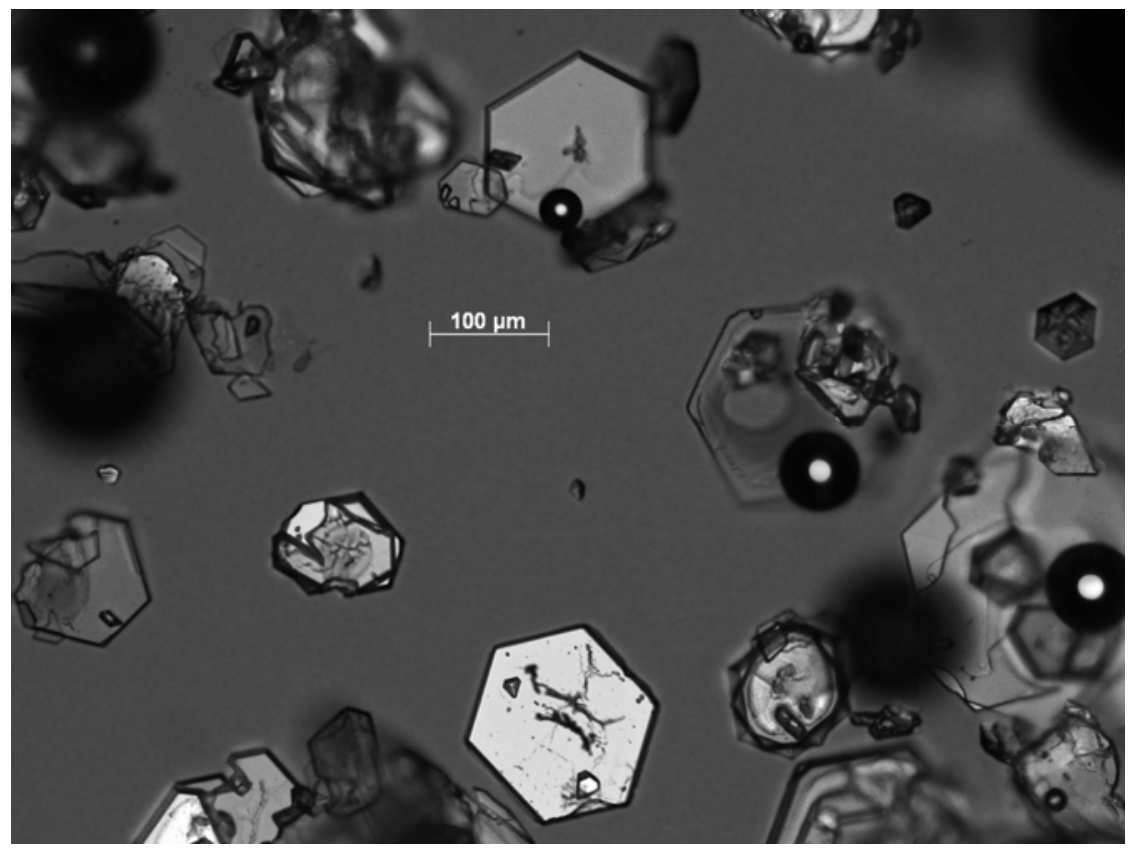

Figure 10. ATK TATB recrystallized from sulfolane produced these large platelets. 


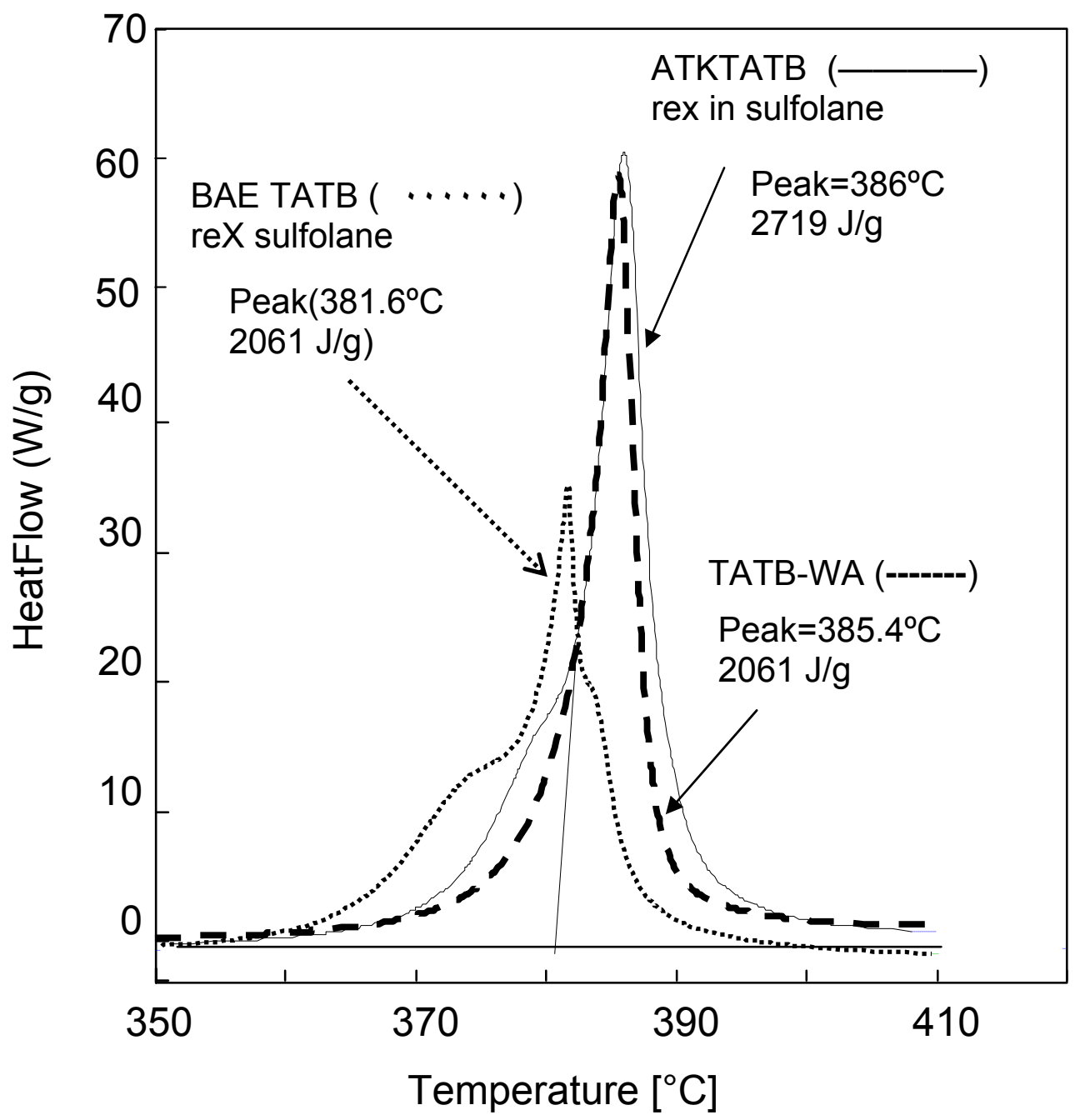

Figure 11. Thermal decomposition of BAE (dotted line) and ATK (solid line) TATBs recrystallized from sulfolane compared to wet aminated TATB (dashed line) showed increased peak temperature compared to original samples. 